\title{
Combined Liver and Kidney Transplantation
}

\author{
Alessandro Milani* and Raffaella Zaccaria
}

Department of Internal Medicine, Università Cattolica S. Cuore, Rome, Italy

\begin{abstract}
A significant proportion of patients requiring liver transplantation (LT) present concomitant renal failure. In case of combined end-stage liver and renal disease simultaneous liver and kidney transplantation (CLKT) is indicated. A liver graft may also protect the kidney from recurrence of specific renal metabolic disease.

CLKT is increasingly available, especially since the introduction of MELD score in organ allocation procedures. The long-term results of CLKT are comparable to those of isolated LT. The indications for CLKT are still not well defined, particularly in the cases with potentially reversible renal injury.

The decision to perform CLKT may be difficult due to our inability at the present time to predict the extent of reversibility of acute or functional renal injury. More studies are required to define reliable predictors of renal recovery, and to understand the complex interactions between the background renal impairment and the functional effects on kidney of decompensated liver disease.
\end{abstract}

Keywords: Renal injury, liver injury, liver transplantation, kidney transplantation, combined liver and kidney transplantation (CLKT).

\section{INTRODUCTION}

The first combined liver and kidney transplantation (CLKT) took place in 1984 [1]. Although CLKT is still not uniformly practiced, the proportion of CLKTs performed worldwide (and namely in the USA) has been steadily increasing in the last years [2], both in terms of absolute numbers and of the proportion of overall liver transplants (LT). The recent introduction of MELD-scoring for allocation of livers, which prioritises patients with renal dysfunction [3-5], may probably account for such an increase, since up to $8 \%$ of LT candidates are reported to present a dialysisrequiring renal failure at the moment of LT [3].

\section{INDICATIONS TO CLKT}

A severe chronic renal failure constitutes an important determinant of post-LT morbidity and mortality, increasing the infectious complications and adversely affecting postoperative long-term renal function and hospital mortality [69]. Moreover, the available clinical data suggest that survival of patients with end-stage renal dysfunction (ESRD) receiving CLKT is significantly better than that of those who receive LT alone, with 1- and 3-year survival rates of $83.6 \%$ vs. $75.1 \%$ and $74.8 \%$ vs. $68.3 \%$, respectively [10].

Current indications for CLKT have been extensively discussed by Chava e coll. [2], and are further summarized in Table 1.

As a general rule, they include combined end-stage liver and renal disease. A liver graft may also protect the kidney from disease recurrence and graft loss in specific renal

*Address correspondence to this author at the Department of Internal Medicine, Università Cattolica S. Cuore, Rome, Italy; Tel: + 0039 6334266; E-mail: alessandro.milani@rm.unicatt.it metabolic diseases such as Primary Hyperoxaluria, Amyloidosis or Methylmalonic Acidaemia.

Table 1. Current Indications for CLKT [2]

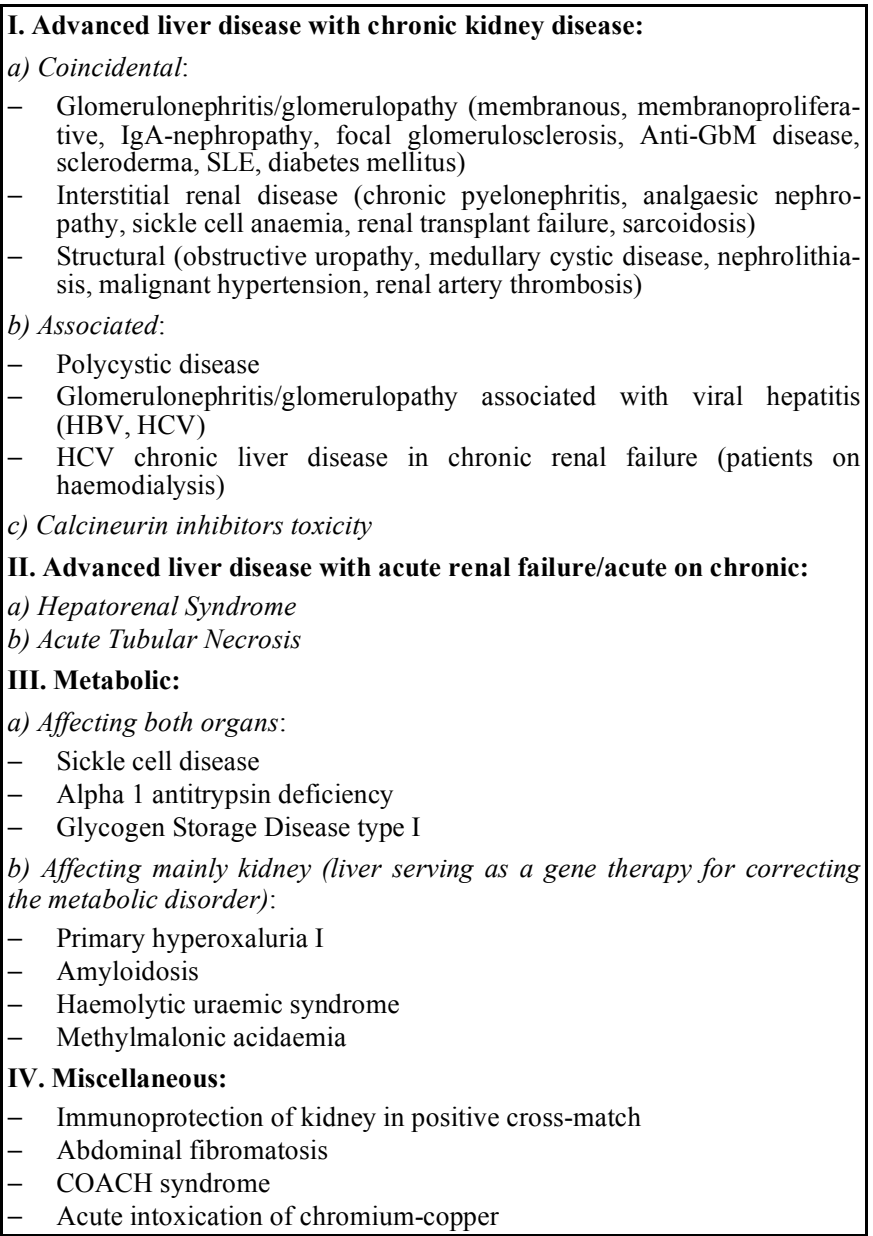


However, the indications to CLKT are still not well defined, being clearly established only for patients with both liver and kidney end-stage disease on haemodialysis. The indications to CLKT are less clear-cut for patients with mildto-moderate chronic renal dysfunction or for those with potentially reversible causes of acute renal failure (including hepatorenal syndrome), because of the lack of availability of reliable markers to predict irreversibility or progression of renal disease. Moreover, the serum creatinine is a poor indicator of kidney function in cirrhosis $[11,12]$.

It may also be difficult to clearly establish a poor prognosis (and therefore an indication to CLKT) in the patients with severe liver disease on haemodialysis, in which transaminase and bilirubin levels are classically low, and ascites may be reduced by renal replacement treatment.

For all these reasons, many questions concerning the appropriate indication and choice of time for combined transplantation still remain unanswered.

Recognising the limitations of available data and the need for more studies, a creatinine clearance $<30 \mathrm{ml} / \mathrm{min}$ in the setting of chronic kidney disease is currently felt to constitute an appropriate threshold for consideration of CLKT [2].

For patients with hepato-renal syndrome or with acute kidney injury, it is normally agreed that a prolonged duration of renal replacement treatment (i.e. above 8 weeks) could be considered an indication for CLKT, portending lack of kidney recovery $[5,13-15]$. Since the longer hepatic-induced kidney ischemia is present the more likely is the permanent renal damage, renal dysfunction of lesser degrees but of prolonged duration may also be associated with a poor kidney function after LT alone. In a recent series [16], the duration of creatinine values of more than $1.5 \mathrm{mg} / \mathrm{dL}$ before LT predicted the serum creatinine six months after transplant. However, the actual elevation of the serum creatinine at transplant (not the duration of elevation), predicted the 12month post-LT creatinine [16].

\section{CLKT OUTCOMES}

In CLKT recipients, short-term patient and graft survival rates are generally lower than with LT alone, with a higher post-transplant mortality due to sepsis and multi-organ failure $[5,17,14]$, as the patients often present worse general conditions and more co-morbidities.

However, the long-term outcome of CLKT seems to be not different from that of LT alone, with a 5-yr patient survival of $70 \%$ and liver graft survival of $65 \%$ after CLKT compared to $72 \%$ and $64 \%$ respectively after LT [14]; the kidney graft half-life has been reported to be slightly less than 10 years for CLKT, compared to 11-12 years for kidney transplants performed from standard donors [18].

However, the results of CLKT are not consistent for all centres, with a 5-year mortality ranging from 48 to $100 \%$ in the different series [2, 5, 14, 17, 19-23].

The use of marginal donors (i.e. age $>55$ years, history of hypertension, donor serum creatinine $>2.0 \mathrm{mg} / \mathrm{dl}$, or non heart-beating donors) is however to be avoided in CLKT, since it is associated with a significantly higher rate of persistent kidney dysfunction, need for post-transplant renal replacement treatment and 1-year mortality [24].

It has been claimed by animal studies that liver engraftment may provide immunologic tolerance $[25,26]$, thus protecting the simultaneously-transplanted kidney from acute rejection $[14,20-22,27,28]$ and permitting lower levels of immunosuppression [21]. The involved immunologic mechanisms may include adsorption and removal of preformed alloreactive antibodies by Kuppfer cells, or their neutralisation by soluble HLA class I antigens expressed by the liver graft [29]. Other potential mechanisms include liver secretion of immuno-modulatory cytokines and the release of donor leukocytes, stem cells or immature dendritic cells, with the subsequent development of haematopoietic microchimerism and donor-specific hypo-responsiveness [30].

Although the 1987-1995 UNOS data did not disclose any reduction in kidney graft rejection in CLKT recipients compared to recipients of the contralateral kidney [31], the analysis of the 1987-2001 UNOS data showed a significantly higher rejection-free survival in CLKT compared to kidney recipients in HLA mismatched groups [17]. Kidney graft loss from chronic rejection seems to be less in CLKT patients $(2 \%)$ compared to kidney $(8 \%)$ and polycystic kidney recipients $(6 \%)$ [17].

\section{NEED FOR A STANDARDIZATION OF THE ORGAN ALLOCATION PROCESS}

As stated above, the practice of CLKT is increasing worldwide. However, since the availability of organs for transplant is limited, deep controversies surround the need for standardized strategies for candidate evaluation, selection, and organ allocation procedures in patients with severe liver and kidney disease [5].

Inappropriate CLKT procedures may in fact result in a post-transplant improvement of native kidney function, with some recipients living with three functioning kidneys. Such a possible outcome, demonstrating how easy might be to draw an incorrect decision for combined transplant, may particularly concern the patients having potentially reversible renal failure, in which the heavy weighting of serum creatinine in the MELD-based organ allocation model grants an incorrect and faster organ availability, overestimating the severity of liver disease.

In fact, if in liver patients the pretransplant serum creatinine is significantly related to wait-list and post-LT survival, this is not true in CLKT candidates with ESRD, in which recipient survival is independent of the pre-transplant serum creatinine [10].

Survival after CLKT compared with LT alone shows clear improve only in liver candidates on dialysis at transplant $[32,10]$; moreover the data from the Scientific Registry of Transplant Recipients show that only less than $2 \%$ recipients of LT alone with a calculated glomerular filtration rate of less than $30 \mathrm{ml} / \mathrm{min}$ (but not on dialysis at the time of transplant) required a further kidney transplant within 1 year of LT [4]. Moreover, the need for chronic dialysis (without a listing for kidney transplant) has not been commonly reported soon after transplant [32]. 
For these reasons, the patients with hepatorenal syndrome not on dialysis should be treated aggressively, reserving CLKT reserved for those with biopsy suggestive of fixed renal damage.

A general consensus has been expressed [2] on the opportunity that any end-stage liver patient with deranged serum creatinine would be studied by a thorough nephrological assessment including urinalysis and imaging.

Newly available markers of kidney failure and renal recovery need to be developed in the evaluation of liver disease [33], in order to grant a reliable assessment of the extent of injury, the risk for progression, and the ability to recover [34-37].

The focus should be on optimal measurements of glomerular filtration (e.g., iothalamate clearances, renal scan), of renal cortical volume, blood flow and oxygen delivery (Duplex-Doppler techniques, paraminohippuric acid clearance, blood oxygen level-determined magnetic resonance imaging), as well as the by-products of injury, matrix protein management, and cytoprotection (i.e. lipid peroxidation products, interleukin 18 and neutrophil gelatinase-associated lipocalin) [33-44].

Renal biopsy is rarely been performed in pretransplant liver evaluation, even when considering a CLKT, probably due to concerns focused upon risks for bleeding [5]. Biopsy safety needs to be carefully evaluated in larger series from experienced centres.

Renal biopsy should be recommended for liver patients in which the cause of a primary renal disease is unclear or the reversibility of renal dysfunction may be uncertain, since its results may potentially alter therapeutic strategies (including the need for CLK) if a progressive kidney disease is diagnosed or substantial renal damage is identified [4547].

A better way to determine the reversibility of renal dysfunction in liver transplant candidates and the degree of liver disease in end-stage renal disease is certainly needed. More studies are required to delineate the clinical, laboratory or histological predictors of renal recovery, and to understand the complex interactions between the background renal impairment and the functional effects on kidney of decompensated liver disease.

The MELD score should be re-examined as an indicator for the need of LT. Perhaps others than MELD markers of poor liver function (such as sodium serum levels, encephalopathy, variceal bleeding, spontaneous bacterial peritonitis, or diuretic-resistant ascites) could be incorporated into the assessment to improve accuracy of organ allocation [48-50]. This may allow a more accurate picture of the severity of liver disease, especially in candidates with ESRD, and help to prioritize patients for LT before the development of eventrelated acute kidney failure, avoiding unnecessary CLKT in potentially reversible renal failures.

\section{REFERENCES}

[1] Margreiter R, Kramar R, Huber C, et al. Combined liver and kidney transplantation. Lancet 1984; 1: 1077-8.
[2] Chava SP, Singh B, Zaman MB, Rela M, Heaton ND: Current indications for combined liver and kidney transplantation in adults. Transpl Rev 2009; 23: 111-9.

[3] Davis CL, Gonwa TA, Wilkinson AH. Identification of patients best suited for combined liver-kidney transplantation: part II. Liver Transpl 2002; 8: 193-211.

[4] Davis CL, Feng S, Sung R, et al. Simultaneous liver-kidney transplantation: evaluation to decision making. Am J Transplant 2007; 7: 1702-9.

[5] Davis CL. Controversies in combined liver-kidney transplantation: indications and outcomes. Transpl Rev 2008; 22: 82-8.

[6] Baliga P, Merion RM, Turcotte JG, et al. Preoperative risk factor assessment in liver transplantation. Surgery 1992; 112: 704-10.

[7] Bilbao I, Charco R, Balsells J, et al. Risk factors for acute renal failure requiring dialysis after liver transplantation. Clin Transplant 1998; 12: 123-9.

[8] Markmann JF, Markmann JW, Markmann DA, et al. Preoperative factors associated with outcome and their impact on resource use in 1148 consecutive primary liver transplants. Transplantation 2001; 72: 1113-22.

[9] Nair S, Verma S, Thuluvath PJ. Pretransplant renal function predicts survival in patients undergoing orthotopic liver transplantation. Hepatology 2002; 35: 1179-85.

[10] Gonwa TA, McBride MA, Anderson K, Mai ML, Wadei H, Ahsan $\mathrm{N}$. Continued influence of preoperative renal function on outcome of orthotopic liver transplant (OLTX) in the US: where will MELD lead us? Am J Transplant 2006; 6: 2651-9.

[11] Gonwa TA, Jennings LS, Mai ML, Stark PC, Levey AS, Klintmalm GB. Estimation of glomerular filtration rates before and after orthotopic liver transplantation: evaluation of current equations. Liver Transpl 2004; 10: 301-9.

[12] Poge U, Gerhardr T, Stoffel-Wagner B, Klehr HU, Sauerbruch T, Woitas RP. Calculation of glomerular filtration rate based on Cystatin C in cirrhotic patients. Nephrol Dial Transplant 2006; 21: 660-4.

[13] Wilkinson AH, Cohen DJ. Renal failure in the recipients of nonrenal solid organ transplants. J Am Soc Nephrol 1999; 10: 1136-44.

[14] Ruiz R, Kunitake H, Wilkinson AH, et al. Long-term analysis of combined liver and kidney transplantation at a single center. Arch Surg 2006; 141: 735-41.

[15] O'Mahony CABN, Vierling JM, Sussman NL, Stribling RJ, Goss JA. Combined liver and kidney transplantation should be considered in patients with hepatorenal syndrome requiring renal replacement therapy greater than 1 week (abst.). Transplantation 2006; 82: 331.

[16] Campbell MS, Kotlyar DS, Brensinger CM, et al. Renal function after orthotopic liver transplantation is predicted by duration of pretransplantation creatinine elevation. Liver Transpl 2005; 11: 1048-55.

[17] Fong TL, Bunnapradist S, Jordan SC, Selby RR, Cho YW. Analysis of the United Network for Organ Sharing database comparing renal allografts and patient survival in combined liverkidney transplantation with the contralateral allografts in kidney alone or kidney-pancreas transplantation. Transplantation 2003; 76: 348-53.

[18] Davis CL. Impact of pre-transplant renal failure: when is listing for kidney-liver indicated? Liver Transpl 2005; 11: S35-44.

[19] Kliem V, Ringe B, Frei U, Pichlmayr R. Single-center experience of combined liver and kidney transplantation. Clin Transplant 1995; 9: 39-44

[20] Jeyarajah DR, McBride M, Klintmalm GB, Gonwa TA. Combined liver-kidney transplantation: what are the indications? Transplantation 1997; 64: 1091-6.

[21] Creput C, Durrbach A, Samuel D, et al. Incidence of renal and liver rejection and patient survival rate following combined liver and kidney transplantation. Am J Transplant 2003; 3: 348-56.

[22] Mosconi G, Scolari MP, Feliciangeli G, et al. Combined liverkidney transplantation with preformed anti-HLA antibodies: a case report. Transplant Proc 2006; 38: 1125-6.

[23] Zanus G, Carraro A, Vitale A, et al. Combined liver and kidney transplantation: analysis of Padova experience. Transplant Proc 2007; 39: 1933-5.

[24] Baker TBAS, Abecassis M. The use of marginal donors is not justified in combined liver kidney transplantation (abs). Transplantation 2006; 82(Suppl 2): 273. 
[25] Calne RY, Sells RA, Pena JR, et al. Induction of immunological tolerance by porcine liver allografts. Nature 1969; 223: 472-6.

[26] Kamada N. The immunology of experimental liver transplantation in the rat. Immunology 1985; 55: 369-89.

[27] Rasmussen A, Davies HF, Jamieson NV, Evans DB, Calne RY. Combined transplantation of liver and kidney from the same donor protects the kidney from rejection and improves kidney graft survival. Transplantation 1995; 59: 919-21.

[28] Gutierrez A, Crespo M, Mila J, Torregrosa JV, Martorell J, Oppenheimer F. Outcome of simultaneous liver-kidney transplantation in highly sensitized, crossmatch-positive patients. Transplant Proc 2003; 35: 1861-2.

[29] Sumimoto R, Kamada N. Specific suppression of allograft rejection by soluble class I antigen and complexes with monoclonal antibody. Transplantation 1990; 50: 678-82.

[30] Murase N, Starzl TE, Tanabe M, et al. Variable chimerism, graft versus-host disease, and tolerance after different kinds of cell and whole organ transplantation from Lewis to brown Norway rats. Transplantation 1995; 60: 158-71.

[31] Katznelson S, Cecka JM. The liver neither protects the kidney from rejection nor improves kidney graft survival after combined liver and kidney transplantation from the same donor. Transplantation 1996; 61:1403-5.

[32] Ojo AO, Held PJ, Port FK, et al. Chronic renal failure after transplantation of a nonrenal organ. N Engl J Med 2003; 349: 93140.

[33] Perco P, Pleban C, Kainz A, et al. Protein biomarkers associated with acute renal failure and chronic kidney disease. Eur J Clin Invest 2006; 36: 753-63

[34] Mishra J, Dent C, Tarabishi L et al. Neutrophil gelatinoseassociated lipocalin (NGAL) as a biomarker for acute renal injury after cardiac surgery. Lancet 2005; 365: 1231-8.

[35] Eddy AA. Progression in chronic kidney disease. Adv Chronic Kidney Dis 2005; 12: 353-65.

[36] Goodman AI, Chander PN, Rezzani R, et al. Heme oxygenase-2 deficiency contributes to diabetes-mediated increase in superoxide anion and renal dysfunction. J Am Soc Nephrol 2006; 17: 1073-81.

[37] Yanagita M. Modulator of bone morphogenetic protein activity in the progression of kidney diseases. Kidney Int 2006; 70: 989-93.
[38] Norman JT, Fine LG. Intrarenal oxygenation in chronic renal failure. Clin Exp Pharmacol Physiol 2006; 33: 989-96.

[39] Day YJ, Huang L, Ye H, Li L, Linden J, Okusa MD. Renal ischemia reperfusion injury and adenosine $2 \mathrm{~A}$ receptor-mediated tissue protection: the role of CD4+ T cells and IFN-gamma. J Immunol 2006; 176: 3108-14.

[40] Sun D, Feng J, Dai C, et al. Role of peritubular capillary loss and hypoxia in progressive tubulointerstitial fibrosis in a rat model of aristolochic acid. Am J Nephrol 2006; 26: 363-71.

[41] Cheng S, Pollock AS, Mahimkar R, Olson JL, Lovett DH. Matrix metalloproteinase 2 and basement membrane integrity: a unifying mechanism for progressive renal injury. FASEB J 2006; 20: 1898900.

[42] Melenhorst WB, van den Heuvel MC, Timmr A, et al. ADAM19 expression in human nephrogenesis and renal disease: associations with clinical and structural deterioration. Kidney Int 2006; 70: $1269-78$.

[43] Mishra J, Ma Q, Prada A, et al. Identification of neutrophil gelatinose-associated lipocalin a s a novel early urinary biomarker for ischemic renal injury. J Am Soc Nephrol 2003; 14: 2534-43

[44] Parikh CR, Mishra J, Thiessen-Philbrook H, et al. Urinary IL-18 is an early predictive biomarker of acute kidney injury after cardiac surgery. Kidney Int 2006; 70: 199-203.

[45] Jouet P, Meyrier A, Mal F, et al. Transjugular renal biopsy in the treatment of patients with cirrhosis and renal abnormalities. Hepatology 1996; 24: 1143-7.

[46] Sam R, Leehey DJ, Picken MM. Transjugular renal biopsy in patients with liver disease. Am J Kidney Dis 2001; 37: 1304-7.

[47] McGuire BM, Julian BA, Bynon J, et al. Glomerulonephritis in patients with hepatitis $\mathrm{C}$ cirrhosis undergoing liver transplantation. Ann Intern Med 2006; 144: 735-41.

[48] Biggins SW, Kim WR, Terrault NA, et al. Evidence-based incorporation of serum sodium concentration into MELD. Gastroenterology 2006; 130: 1652-60.

[49] Hou TI, Lin HC, Wu JC, et al. Limitation of the model for endstage liver disease for outcome prediction in patients with cirrhosisrelated complications. Clin Transplant 2006; 20: 188-94.

[50] Silberhumer GR, Hetz H, Rasoul-Rockenschaub S, et al. Is MELD score sufficient to predict not only death on waiting list, but also posttransplant survival. Transpl Int 2006; 19: 270-4.

\section{(C) Milani and Zaccaria; Licensee Bentham Open.}

This is an open access article licensed under the terms of the Creative Commons Attribution Non-Commercial License (http:/creativecommons.org/ licenses/by-nc/3.0/), which permits unrestricted, non-commercial use, distribution and reproduction in any medium, provided the work is properly cited. 